\title{
GENETIC ALGORITHM FOR OIL SPILL AUTOMATIC DETECTION USING SYNTHETIC APERTURE RADAR
}

\author{
MARGHANY M. \\ MANSOR S.
}

\author{
Geospatial Information Science Research \\ Centre, Faculty of Engineering \\ Universiti Putra Malaysia \\ 43400 UPM, Serdang, Selangor, Malaysia
}

Received: $15 / 05 / 2014$

Accepted: 07/12/2015

Available online: 07/12/2015

*to whom all correspondence should be addressed: e-mail: magedupm@hotmail.com

\section{ABSTRACT}

This work has exploited a Genetic algorithm for oil spill automatic detection. This is implemented to sequences of RADARSAT-2 SAR ScanSAR narrow single beam data in the Gulf of Mexico. The study shows that the implementation of crossover is generated an accurate oil slick pattern. This is confirmed by using the receiver-operational characteristics (ROC) curve. The ROC curve endorses the existence of oil slick footprints with $90 \%$, which is larger than other surrounding environment features. It can be pronounced that ScanSAR Narrow single beam is the tremendous promise sensor for oil spill detection and survey. In conclusion, the Genetic Algorithm can be used as an automatic detection tool for oil spill.

Keywords: Oil Slick, Gulf of Mexico, RADARSAT-2 SAR, ScanSAR narrow beam, Genetic algorithm

\section{Introduction}

Oil spill pollution has aincredible reliability in damaging the marineenvironment. Oil spill that floats on top of water, as well as decreasing the fauna populations, affects the food chain in the ecosystem (Alpers 2002; Brekke and Solberg 2005; Garcia et al., 2013). In point of fact, oil spills reduce the sunlight penetrates through the water column, which is limiting the photosynthesis of marine plants and phytoplankton. Besides, marine mammal for instance, disclosed to oil spill their insulating capacities are reduced, and so making them more vulnerable to temperature variations and much less buoyant in the seawater.As a result, the oil coats the fur of sea otters and seals, reducing its insulation capacities and leading to body temperature variations and hypothermia. Taking in of the oils cause dehydration and damageto the ingestion system (Fiscella et al., 2000).

Over recent years, there has been an explosive increase in marine pollution. The Deepwater Horizon oil spill in 2010, for instance, is the most critical marine pollution disaster has occurred in the history of the petroleum industry. The fire burned for 36 hours before the rig sank, and hydrocarbons leaked into the Gulf ofMexico before the well was closed and sealed (Figure 1). In this regard, Figure 1a shows the status of Deepwater Horizon prior to explosion while Figure $1 \mathrm{~b}$ shows dark clouds of smoke and fire emerge as oil burns during a controlled fire in the Gulf of Mexico. This disaster has domineered by three months of oil flows in coastal waters of the Gulf of Mexico. As result,the Deepwater-Horizon oil spill has serious effects on feeble maritime species, wildlife habitats,Gulf's fishing activities, coastal ecologies and tourism industries. Besides, the oil spill and its cleanup cause health problems. Also, Deepwater-Horizon spilled nearly five million barrels, creating it the world's massive accidental marine oil spill. Oil spills, thus, are hard to control attributable to the influence of coastal hydrodynamic such as wave, current, and tide. 
Under this circumstance, advanced technologies are required toaccomplish accurate surveying, and monitor of oil marine pollution spreading (Garcia-Pineda et al., 2013).

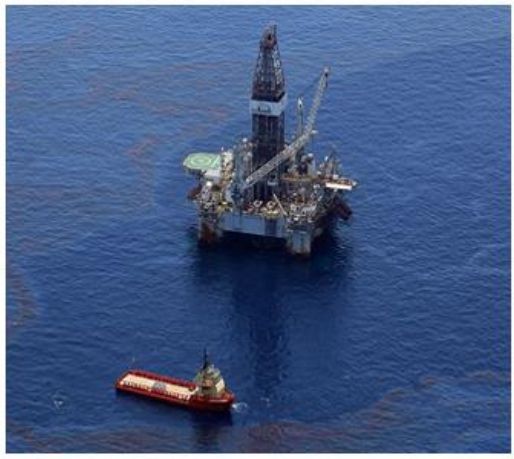

(a)

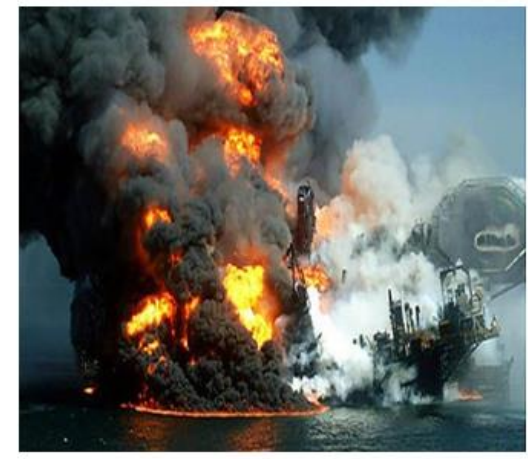

(b)

Figure 1. Aerial photographs for Deepwater Horizon (a) prior to explosion and (b) post to explosion

Consistent with the work of Topouzelis et al., (2007); Topouzelis et al., (2009); Marghany and Hashim (2011), synthetic aperture radar (SAR) improves oil spill detection by us in various precious approaches. SAR has various tools to detect and survey oil spills which are vessels, airplanes, and satellites (Zhang et al., 2012). Vessels can detect oil spills at sea, by covering restricted areas, for example, $2500 \mathrm{~m} \times 2500$ $\mathrm{m}$ then they are equipped with the navigation radar (Zhang et al., 2011). Airplanes and satellites are the main tools that are used to record sea-based oil pollution (Skrunes et al., 2012). Several SAR sensors are involved in the oil spill detection and survey. These data are from ERS-1/2, (Brekke and Solberg, 2005) ENVISAT (Marghany, 2013), ALOS, (Zhang et al., 2012), RADARSAT-1/2, (Zhang et al., 2012) and TerraSAR$X$ (Velotto et al., 2011) which have been globally, used to identify and monitor the oil-spill. Further, Airborne SAR sensors like Uninhabited Aerial Vehicle Synthetic Aperture Radar (UAVSAR, by JPL, L-band) with a $22-\mathrm{km}$-wide ground swath at $22^{\circ}$ to $65^{\circ}$ incidence angles (Zhang et al., 2012) and E-SAR, (by DLR, multi-land) have also proven their excellent potential for monitoring coastal zone oil pollution. Recently, the multipolarimetric SAR high-resolution data have become a vital research area for oil spill detection (Skrunes et al., 2012; Shirvany et al., 2012).

Nonetheless, oil spill monitoring and detection using SAR technology, data are scarcely task. Because of barely discrimination between oil spill and other features of look-alike, low wind zone and shadows which appear as dark patches in SAR data. Although the difficulties of oil spill automatic in SAR data, significant achievements have been made in the past decades. Perspectively, Frate et al. (2000) proposed the semiautomatic detection of oil-spill by using neural network,for which the main used parameter is a vector describing features of an oil-spill candidate. Topouzelis et al., (2007); Topouzelis et al., (2009) and Marghany and Hashim, (2011) confirmed that the neural network could be used precisely to discriminate among oil-spill and look-alike in SAR data. Topouzelis et al., (2007) used neural networks in both dark patches detection and oil-spill classification. In their experiment, $94 \%$ of the dark patches segmentation and $89 \%$ accuracy of classification were obtained respectively. Topouzelis et al., (2009) also carried out a detailed robustness examination of the combinations derived from 25 commonly used features, andfound that a combination of 10 features yields the most accurate results.Therefore, Topouzelis et al., (2009) reported that most studies used the low resolution SAR data, such as quick-looks, with the nominal spatial resolution of $100 \mathrm{~m} \times 100 \mathrm{~m}$, to detect oil spills. In this regard, quick looks' data are sufficient for monitoring large scale area of $300 \mathrm{~km} \times 300 \mathrm{~km}$. On the contrary, they cannot efficiently detect small and fresh spills.

Marghany and Hashim, (2011) developed comparable automatic detection procedures for oil spill pixels in Multimode RADARSAT-1 SAR (Standard beam S2, Wide beam W1 and fine beam F1). These procedures involved the post supervised classification (Mahalanobis), and neural network (NN). They found that NN 
shows a higher performance in automatic detection of oil spill in RADARSAT-1 SAR data compared with the Mahalanobis classification with a standard deviation of 0.12. Recently, Skrunes et al., (2012), nevertheless, reported several disadvantages are associated with the current SAR sensors based oil spill detection. Furthermore,they stated that the SAR sensors cannot detect the thickness distribution, volume, oil-water emulsion ratio and chemical properties of oil spills. In this context, they recommended to use multi-polarization acquisitiondata,such as RADARSAT- 2 and TerraSAR- $X$ satellites. They settled the multi-polarization data accurately prejudice between mineral oil slicks and biogenic slicks. Recently, Garcia et al., (2013) developed the Textural Classifier Neural Network Algorithm (TCNNA) to map oil-spill by combining ENVISAT ASAR data and wind model outputs (CMOD5) using a combination of two neural networks. They stated TCNNA can be used as a semi-automatization tool for oil spill detection and provides fast and precise overview of oil spill footprint in ENVISAT ASAR data. Finally, they concluded that TCNNA performance is a function of wind conditions.

Thus quick response in case of a marine oil spill accident such as the Deepwater Horizon is required standard tool.It was hypothesized that dark patches, either oil spill, look-alike, or low wind zone in SAR data can be automatically detected and discriminated against using Genetic Algorithm (GA). Previous work has imposed post classification techniques (Marghany and Mazlan, 2011) or artificial neural network (Topouzelis et al., 2009; Garcia et al., 2013). These are considered as semi-automatic techniques. The main objective of this work is to examine GA (Marghany, 2013) for oil spill automatic detection in RADARSAT-2 SAR satellite data.

\section{Methods}

\subsection{Study Case}

On April 20, 2010 theDeepwater Horizon, offshore oil-drilling rig exploded, while working on a wall on the seafloor in the Gulf of Mexico. The blast occurred 41 miles from the Louisiana coast (Figure 2). For nearly three months, oil leaked from the Macondo well at a rate estimated between 35,000 and 60,000 barrels a day. In other words, there are 42 gallons in a barrel, that continued to flow until mid-July 2010 . In all, the well spilled 4.9 million gallons: the biggest offshore oil spill in history. Further, the oil slick spread quickly over the ocean surface, covering 1,500 square kilometers ( 580 sq miles) by April 25 and over 6,500 square kilometers (2,500 sq miles) by the beginning of May (Garcia-Pineda et al., 2013).

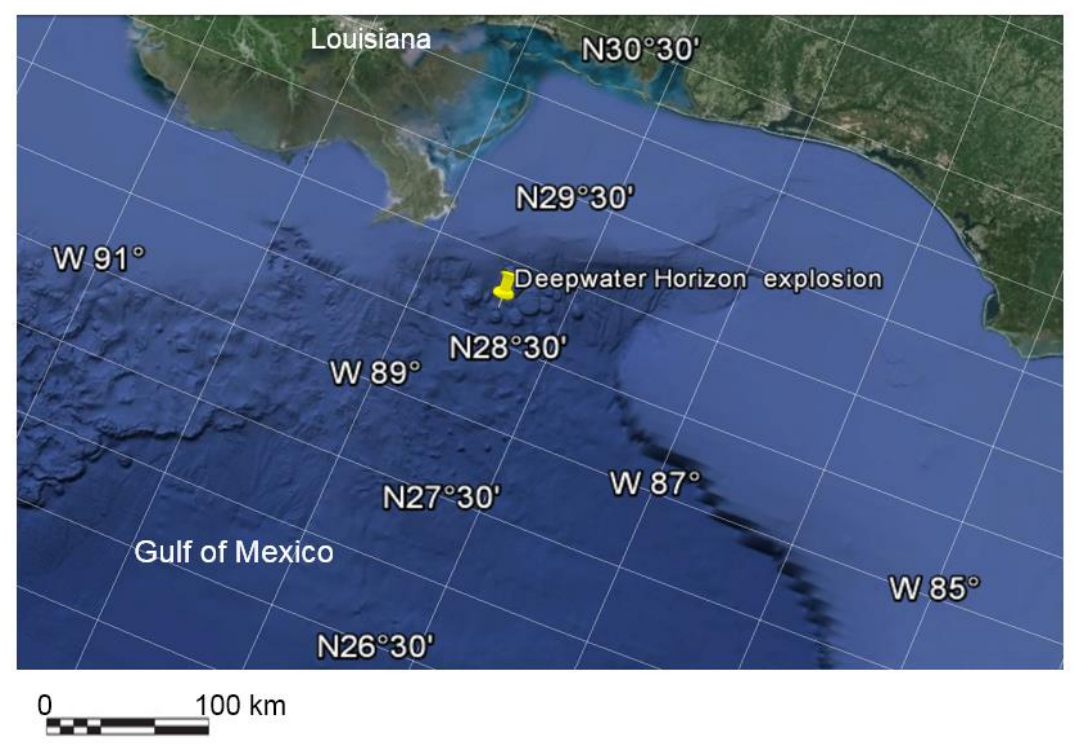

Figure 2. Location of Deepwater Horizon Blowout, Gulf of Mexico 


\subsection{Data Set}

In this study, RADARSAT-2 SAR data with RADARSAT-2 in ScanSAR narrow single beam (Table 1) on April $27^{\text {th }}, 2010$, May $1^{\text {st }} 2010$, May $3^{\text {rd }}, 2010$, and May $5^{\text {th }} 2010$ are carried out for oil spill detection in the Gulf of Mexico. The Satellite has a synthetic aperture radar (SAR) with multiple polarization modes, including a fully polarimetric mode in which $\mathrm{HH}, \mathrm{HV}, \mathrm{VV}$ and $\mathrm{VH}$ polarized data are acquired. Thehighest resolution is $1 \mathrm{~m}$ in Spotlight mode ( $3 \mathrm{~m}$ in Ultra Fine mode) with $100 \mathrm{~m}$ positional accuracy requirement. In ScanSAR wide beam mode the SAR has a nominal swath width of $500 \mathrm{~km}$ and an imaging resolution of $100 \mathrm{~m}$. An oil platform located $70 \mathrm{~km}$ from the coast of Louisiana sank on Thursday, April $22^{\text {nd }}, 2010$ in the Gulf of Mexico spilling oil into the sea (RADARSAT-2, 2014).

Table 1. RADARSAT-2 Characteristics

\begin{tabular}{|l|c|}
\hline RADARSAT-2 Characteristics & Values \\
\hline Model & ScanSAR Narrow \\
\hline Band & $\mathrm{C}($ single) \\
\hline Band Width $(\mathrm{MHz})$ & 100 \\
\hline Swath Width $(\mathrm{km})$ & $300 \times 300$ \\
\hline Polarization & $\mathrm{HH}$ \\
\hline Nominal Resolution $(\mathrm{m})$ & $50 \times 50$ \\
\hline Center Frequency $(\mathrm{GHz})$ & 5,405 \\
\hline Incident Angel & $31^{\circ}-47^{\circ}$ \\
\hline
\end{tabular}

\subsection{Genetic algorithm}

Consistent with Sivanandam and Deepa (2008), the genetic algorithm (GA) is an important tool in the fields of artificial intelligence and the computer science. GA is considered as an optimal search and evolutionary algorithm that mimics the processes of natural selection. In other words, GA spawns solutions to optimization problems using techniques stimulated by natural evolution, such as inheritance, mutation, selection, and crossover.

In the word of Kahlouche et al., (2002), the genetic algorithm (GA) differs from classification algorithms. In classification algorithms, a single point at every iteration is generated. Moreover, classification algorithms correspondingly choose the next point in the classification by a deterministic computation. In contrast, the genetic algorithm (GA) generates a population of cells at every iteration, where the superlative cell in the population approaches an optimal solution. Moreover, the GA, implements probabilistic transition rules not deterministic rules as compared to classification algorithms (Marghany, 2013).

A large population of random chromosomes with different SAR backscatters is created at the beginning of a run of a genetic algorithm. Each one, when decoded will represent a different solution to the problem at hand. In this circumstance, there are $N$ chromosomes in the initial population. Then, the following steps are repeated until a solution is accurately achieved: (i) Test each chromosome of SAR backscatter to find how excellent it is at solving the problem at hand and assign a fitness score accordingly. The fitness score is a measure of how good that chromosome is at solving the problem at hand; (ii) select two members from the current population. The chance of being selected is proportional to the chromosomes' fitness; (iii) dependent on the crossover rate crossover the bits from each chosen chromosome at a randomly chosen point; (iv) step through the chosen chromosomes' bits and flip dependent on the mutation rate; and $(v)$ repeat step ii, iii and iv until a new population of $N$ members have been created.

\subsubsection{Data organization}

Let the entire backscatter of dark patches in SAR data are $\left[\beta_{1}, \beta_{2}, \beta_{3}, \ldots, \beta_{K}\right]$ where $K$ is the total number backscatter of dark patches in the SAR data. Therefore, $K$ is made up from genes which is representing the backscatter $\beta$ of dark patches and its surrounding environment and genetic algorithms is started with the population initializing step. Following Marghany, (2013), a constrained multi-objective problem for oil spill discrimination in SAR data deals with more than one objective and constraint namely look-alikes, for 
instance, currents, eddies, upwelling or downwelling zones, fronts and rain cells). The general form of the problem is adapted from Sivanandam and Deepa (2008) and described as

Minimize $f(\beta)=\left[f_{1}(\beta), f_{2}(\beta), \ldots, f_{k}(\beta)\right]^{\top}$

Subject to the constraints:

$$
\begin{aligned}
& g_{i}(\beta \leq 0, i=1,2,3, \ldots l) \\
& h_{j}(\beta \leq 0, j=1,2,3, \ldots J) \\
& \beta_{s} \leq \beta \leq \beta_{U}
\end{aligned}
$$

where, $f_{1}(\beta)$ is the $i$-th pixel backscatters $\beta$ in SAR data, $g_{i}(\beta)$ and $h_{j}(\beta)$ represents the $i$-th and $j$-th constraints of backscatter in raw direction and column direction, respectively. $\beta_{L}$ and $\beta_{U}$ are the lower and upper limit of values of the backscatter.The transition rules for the cellular automata oil spill detection is designed using the input of different backscatter values $\beta$ to identify the slick conditions required in the neighborhood pixels of kernel window size of $7 \times 7$ pixels and lines for a $\beta$ pixel to become oil slick. These rules can be summarized as follows:

1. IF test pixel is sea surface, OR current boundary features THEN $\beta \geq 0$ not oil spill.

2. IF test pixel is dark patches (low wind zone, OR biogenic slicks OR shear zones) $\beta \leq 0$ THEN It becomes oil slick if its.

\subsubsection{Population Initializing}

Let $P_{i}^{j}$ is a gene which corresponds to backscatter of dark pixels and its surrounding pixels. Consequently, $\mathrm{P}_{\mathrm{i}}^{\mathrm{j}}$ is randomly selected and representing both of backscatter variations of dark patches and its surrounding environmental pixels. Moreover, i varies from 1 to $\mathrm{K}$ and $\mathrm{j}$ varies from 1 to $\mathrm{N}$ where $\mathrm{N}$ is the population size.

\subsubsection{The Fitness Function}

Following Kahlouche et al., (2002) and Marghany, (2013), a fitness function is selected to determine the similarity of each individual backscatter of dark patches in RADARSAT-2 SAR data. Then the backscatter of dark patches in RADARSAT-2 SAR can be symbolized by $\beta_{\mathrm{i}}$ where $\mathrm{i}=1,2,3, \ldots, \mathrm{K}$ and the initial population $\mathrm{P}_{\mathrm{i}}^{\mathrm{j}}$ where $j=1,2,3, \ldots, N$ and $i=1,2,3 \ldots, K$. Formally, the fitness value of $f\left(P^{j}\right)$ each individual of the population is computed as follows:

$f\left(P^{j}\right)=\left[\sum_{i=1}^{K}\left|P_{i}^{j}-\beta_{i}\right|\right]^{-1} j=1, \ldots, N$

where, $\mathrm{N}$ and $\mathrm{K}$ are the number of individuals of the population used in fitness process. Generally, Equation 5 used to determine the level of similarities of dark patches that belong to oil spill in RADARSAT2 SAR data.

\subsubsection{Selection Step}

The key parameter in the selection step of genetic algorithm which is chosen the fittest individuals $f\left(P^{j}\right)$ from the population $P_{i}^{j}$. The threshold value $\tau$ is determined by the maximum values of fitness of the population $\operatorname{Max} f\left(P^{j}\right)$ and the minimum values of fitness of the population of $\operatorname{Min} f\left(P^{j}\right)$. Indeed, in the next generations, this step serves the populations $P$. Therefore, the values of the fittest individuals dark patches in RADARSAT-2 SAR data are greater identifies threshold $\tau$ which is given by

$$
\tau=0.5\left[\operatorname{Max} f\left(P^{j}\right)+\operatorname{Min} f\left(P^{j}\right)\right]
$$


Equation 6 used as selection step to determine the maximum and minimum values of fitness of the population, respectively. This is considered as a dark patches' population generation step in the GA algorithm.

\subsubsection{The reproduction step}

According to Sivanandam and Deepa (2008), the genetic algorithm is mainly a function of the reproducing step which involves the crossover and mutation processes on the backscatter population $P_{i}^{j}$ in SAR data. In this regard, the crossover operator constructs the $P_{i}^{j}$ to converge around solutions with high fitness. Thus, the closer the crossover probability is to 1 and the faster is the convergence (Marghany, 2013). In crossover step the chromosomes interchange genes. A local fitness value effects each gene as

$$
f\left(P_{i}^{j}\right)=\left|\beta_{i}-P_{i}^{j}\right|
$$

Then the crossfire between two individuals consists to keep all individual populations of the first parent which have a local fitness greater than the average local fitness $f\left(P_{a v}^{j}\right)$ and substitutes the remained genes by the corresponding ones from the second parent. Hence, the average local fitness is defined by:

$$
f\left(P_{a v}^{j}\right)=\frac{1}{K} \sum_{i=1}^{K} f\left(P_{i}^{j}\right)
$$

Therefore, the mutation operator denotes the phenomena of extraordinary chance in the evolution process. Truly, some useful genetic information regarding the selected population could be lost during reproducing step. As a result, mutation operator introduces a new genetic information to the gene pool (Marghany 2013).

\subsubsection{Morphological operations}

Morphological operation on the selected individuals is performed prior to the crossover and the mutation processes. In the crossover process, the chance that two chromosomes will swap their bits. A good value for this is around 0.7. Crossover is performed by selecting a random gene along the length of the chromosomes and swapping all the genes after that point (Michalewicz, 1994). In other words, choose a random bit along the length, say at position 9, and swap all the bits after that point.

In the mutation process, the chance that a bit within a chromosome is flipped ( 0 becomes 1,1 becomes $0)$. This is usually a very low value for binary encoded genes, say 0.001 . Hence every time chromosomes are chosen from the population the algorithm first checks to investigate if crossover is applied and then the algorithm iterates down the length of each chromosome mutating the bits if applicable (Davis, 1991). This is to exploit connectivity property of the RADARSAT-2 SAR. The morphological operators are implemented through the reproduction step: (i) closing followed by (ii) opening. In this regard, the accuracy of dark patch segmentations are function of the size and the shape of the structuring element. Therefore, kernel, window size of a square of structuring of $7 \times 7$ is chosen to preserve the fine details of oil spill in RADARSAT-2 SAR (Sivanandam and Deepa, 2008).

\section{Results and discussion}

The GA is trained on four RADARSAT-2 SAR Scan narrow beam (SCNB) data (Figure 3), whereas the dark patches are identified and examined. The SCMB data contained the confirmed oil spills that occurred 70 $\mathrm{km}$ from the coast of Louisiana, in the Gulf of Mexico. Clearly, in these SCNB data, the oil slick footprints are rapidly growth from April $27^{\text {th }}, 2010$, to May $5^{\text {th }}, 2010$ (Figure 3). Figure 3 shows the oil slicks and sheen extended across 19,112 square miles $\left(49,500 \mathrm{~km}^{2}\right)$ in the Gulf of Mexico. In addition, the oil slick spun into a counter clockwise direction. This is attributed to the influence of the Gulf Stream. Nevertheless, the RADARSAT-2 SAR data did not show the oil slick footprints coincided with the loop current of the Gulf of Mexico. According to Zangari (2010), the thick oil slick caused the splitting of the loop current in the Gulf of Mexico. 


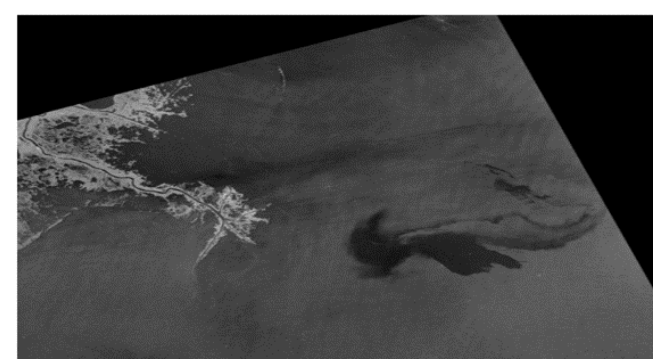

(a)

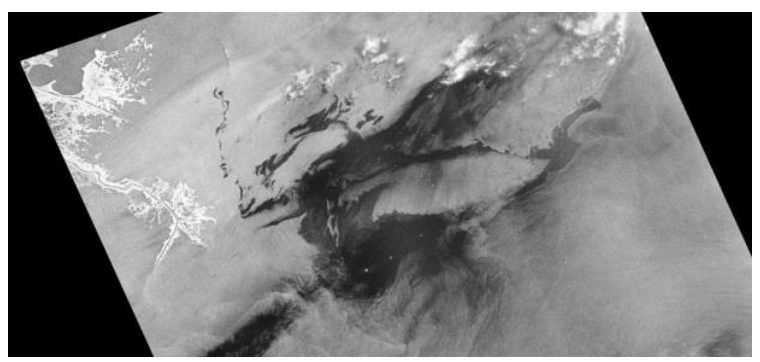

(c)

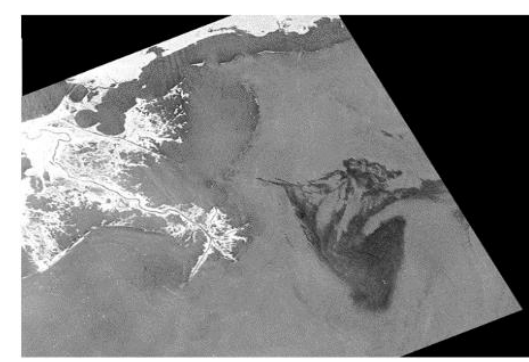

(b)

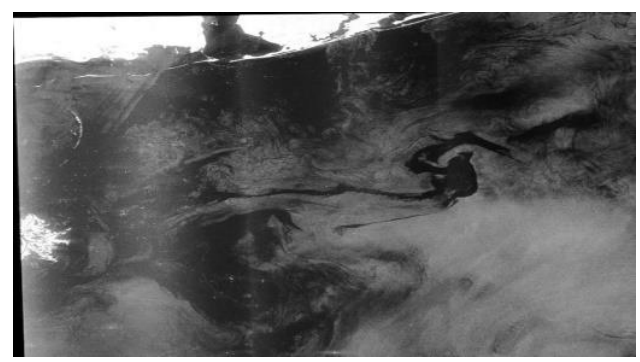

(d)

Figure 3. RADARSAT-2 SAR Scan Narrow beam SCNB data in (a) April $27^{\text {th }}$, (b) May $1^{\text {st }}$, (c) May $3^{\text {rd }}$, and (c) May $5^{\text {th }} 2010$

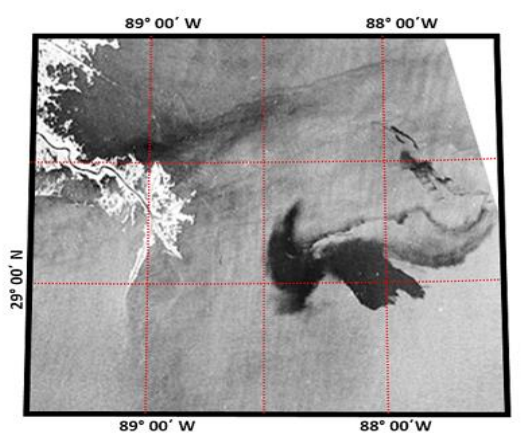

(a)

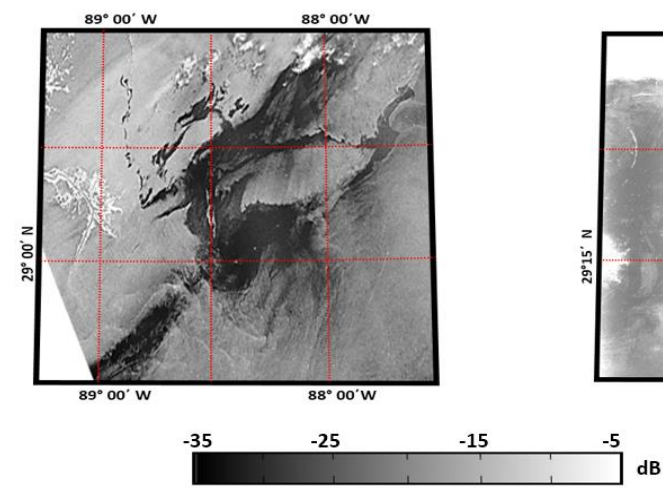

(c)

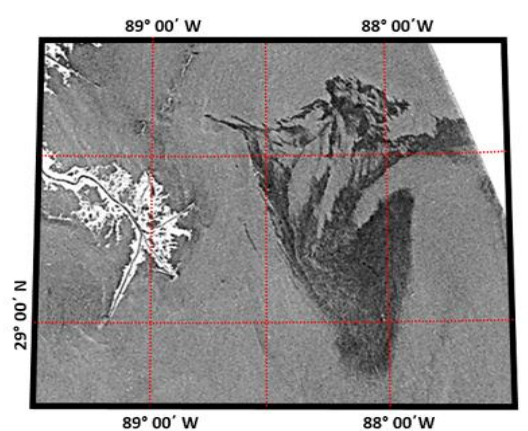

(b)

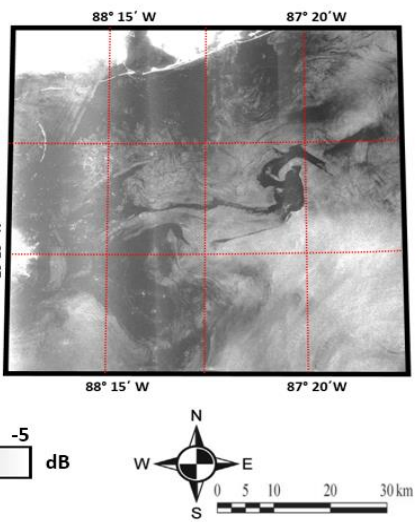

(d)

Figure 4. Backscatter variations during (a) April $27^{\text {th }}$, (b) May $1^{\text {st }}$, (c) May $3^{\text {rd }}$, and (d) May $5^{\text {th }} 2010$ 
Evidently, the oil spillcovered area more than $150 \mathrm{~km}$ in the Gulf of Mexico, which has the darkest tone than the surrounding water, as well as some boats in the area (Figure 4). In addition, the most extremely advanced of the SCNB data is its and a high revisit period. Figure 4 shows the variation of the average backscatter intensity along the oil slick footprints. The average backscattered intensity is damped by -35 $\mathrm{dB}$ to $-30 \mathrm{~dB}$ and decreased with time as the oil slick footprint increases gradually (Figure 4). Nevertheless, ship footprints are dominated by highest backscatter of $-5 \mathrm{~dB}$ (Figure 5). This is because of the fact that SCNB mode has nominal near and far resolutions of $7 \mathrm{~m}$ (MDA 2009).

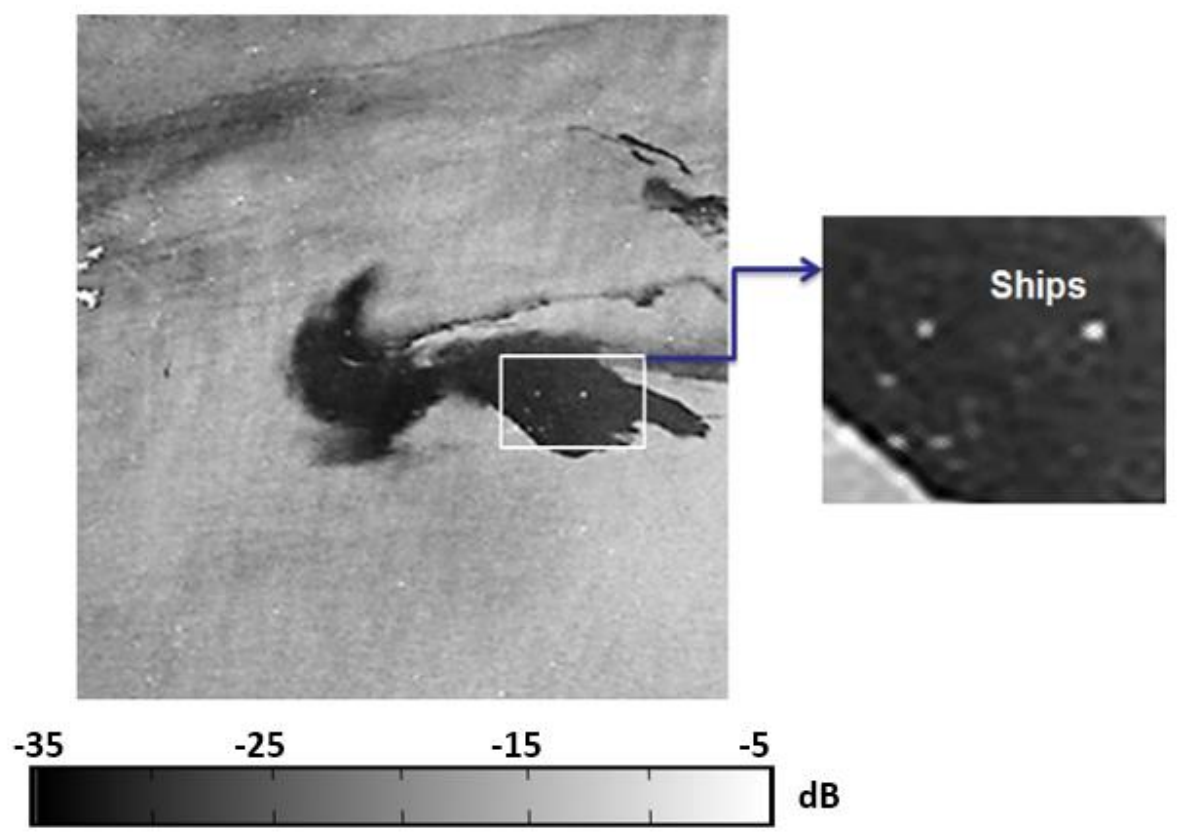

Figure 5. Backscatter of ship pixels

The SCNB mode provides images of very wide swaths in a single pass of the satellite with single linear copolarization of $\mathrm{HH}$ and pixel spacing of 25 range $\times 25$ azimuths $(\mathrm{m})$. The SCNB provides coverage over the shallow incident angle range $31^{\circ}$ to $47^{\circ}$. The selection of this data source is because of its large swath (300 $\mathrm{km})$, acceptable pixel size, spacing $(25 \mathrm{~m})$, high temporal resolution ( $2 / 3$ side-lap pass within 7 days) and lesser volume of data. The C-band and shallow incidence angle $\left(31^{\circ}-47^{\circ}\right)$ have been found suitable for identification of oil slick footprints. The sensitivity of water surface roughness created by a wind-induced ripple to SAR backscatter is reduced by using HH polarization and a large incidence angle (Ivanov et al., 2002 and Choudhury and Chakraborty 2006). Further Ivanov et al., (2002) confirmed that the RADARSAT$1 \mathrm{SAR}$, in its ScanSAR narrow mode with swath width that exceeds $300 \mathrm{~km}$, is an attractive tool for marine oil pollution detection.

Figure 6 shows an example of the crossover process with 10 individuals. In this 10 individuals, the positive dark patches are represented oil spill pixels (Figure 6a), while negative, dark patches represent the surrounding pixels. Accordingly, every cell is compared with the corresponding cell in the others to determine either to be positive or negative. According to Marghany, (2013) in the GA procedures, cell has a positive value and must be strengthened when cell in the intermediate prototype has a value larger than zero and greater than threshold 's value. In this regard, these cells are represented an oil spill event in RADARSAT-2 SAR data. On the contrary, the cell represents look-alikes when it has a negative value. As a result, the cell in the intermediate prototype is less than zero and threshold 's value. In this regard, this cell must be diminished (Figure 6b). The variation cell value (positive or negative) is a function of dissimilarity of the comparable cells (Davis, 1991). This study confirms and extends the capabilities of the GA introduced by Kahlouche et al., (2002) and Marghany (2013). 


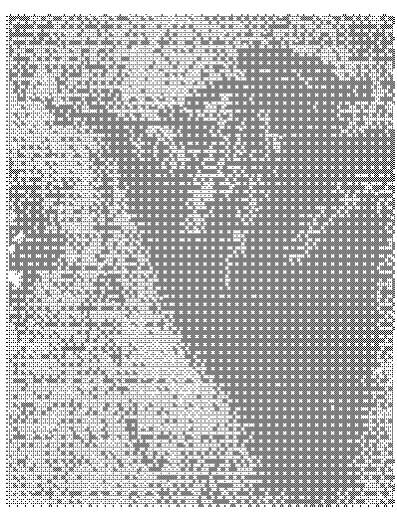

(a)

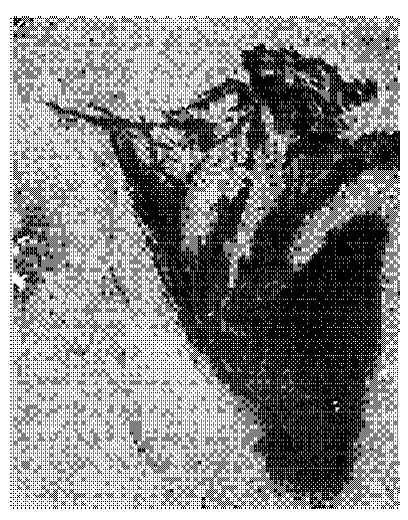

(b)

Figure 6. Crossover procedures (a) resulting from an individual prior cancellation and (b) after cancellation

Obviously, the genetic algorithm is able to isolate oil spill dark pixels from the surrounding environment. In other words, look-alike,low wind zone, sea surface roughness, and land are marked by white color while oil spill pixels are marked all black (Figure 7).

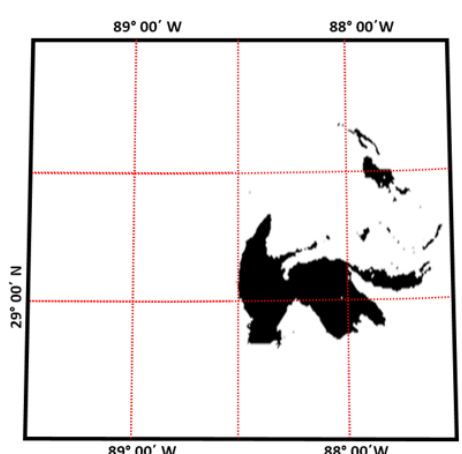

(a)

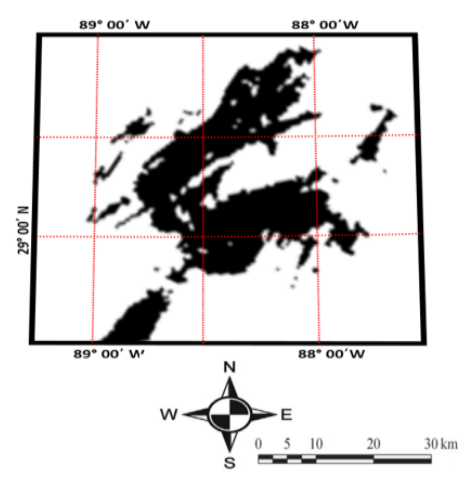

(c)

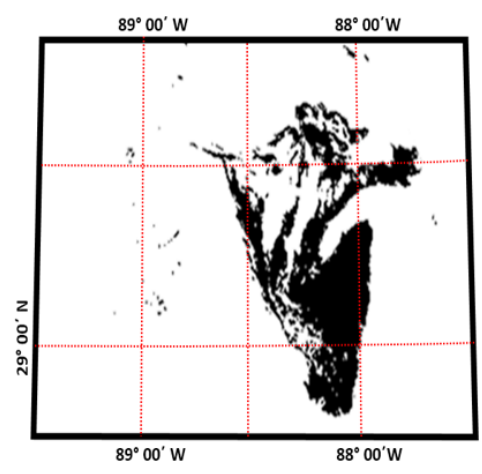

(b)

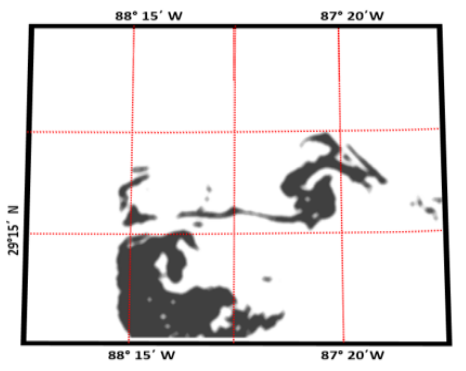

Oil spill

(d)

Figure 7. Genetic algorithm of oil spill automatic detection in RADARSAT-2 ScanSAR Narrow during (a) April $27^{\text {th }}$, (b) May $1^{\text {st }},\left(\right.$ c) May $3^{\text {rd }}$, and (d) May $5^{\text {th }} 2010$ 
Further, Figure 8 shows the results of the GA, where $100 \%$ of the oil slick footprints in the test set are correctly classified. This study is not similar to previous work done by Marghany and Hashim, (2011). The dissimilarity is because this work provides the automatic classifier based on the GA but Marghany and Hashim, (2011) work is considered as a semi-automatic tool for oil spill detection. In contrast with previous studies of Fiscella et al., (2000) and Marghany and Mazlan, (2011), the Mahalanobis classifier provides a classification pattern of oil spill where the slight oil spill can distinguish from medium and heavy oil spill pixels. Nevertheless, this study is consistent with Topouzelis et al., (2009). In consequence, the genetic algorithm extracted oil spill pixels automatically from surrounding pixels without using different segmentation algorithm as stated in Skrunes et al., (2012).

The receiver-operator characteristics (ROC) curve in Figure 8 indicates a significant difference in the discriminated between oil spill, look-alikes and sea surface roughness pixels. In terms of ROC area, the oil spill has an area difference of $90 \%, 7 \%$ for sea roughness and 3\% for look -alike, respectively. Table 2 also indicates that GA has highest performance for oil spill detection with smallest standard error of 0.11 and a $\rho$ value of 0.0000057 (Table 2) which confirms the study of Marghany, (2013). This suggests that the genetic algorithm is an excellent classifier to discriminate region of oil slicks from surrounding water features.

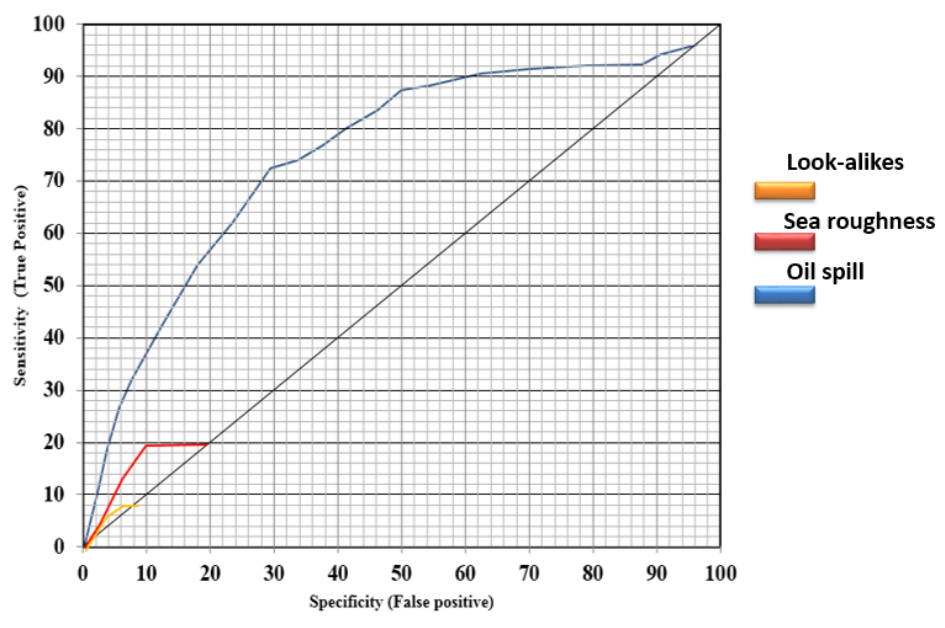

Figure 8. ROC for oil spill discrimination using Genetic Algorithm (GA)

Table 2. Accuracy of feature detections in SCANB data

\begin{tabular}{|c|c|c|c|}
\hline Features & Area under Curve (\%) & Standard Error & $\mathbf{P}<\mathbf{0 . 0 0 5}$ \\
\hline Oil Spill & 90 & 0.11 & 0.0000057 \\
\hline Look-alikes & 3 & 0.14 & 0.0000085 \\
\hline Sea Surface Roughness & 7 & 12 & 0.0000081 \\
\hline
\end{tabular}

This is because of genetic algorithm contains the crossover procedure. In this regard, a new population is generated in each crossover process. As a result, individual populations are examined by the fitness function and added to the population. Thus, new populations are continuously generated based on the dissimilarities between the two successive fitness values. In addition, the crossover procedure produced a more refined oil spill pattern by despeckle and maintenance the morphology of oil spill pattern features. This is because of the fitness function is used to sustenance the oil spill pixel classification. Indeed, fitness function selected oil spills morphological pattern which is close to the requested spill prototype.

\section{Conclusions}

This study has operated the genetic algorithm for oil spill detection in RADARSAT-2 SAR SCNB data. In this study, four SCNB data acquired along the Gulf of Mexico on April $27^{\text {th }} 2010,1^{\text {st }}$ May 2010, $3^{\text {rd }}$ May 2010 
and $5^{\text {th }}$ May 2010. The oil spills detected in SCNB data dominated by lowest backscatter of $-40 \mathrm{~dB}$ while the ship footprints dominated by the highest backscatter of $-5 \mathrm{~dB}$. The study shows that crossover process, and the fitness function generated accurate pattern of oil slick in SCNB data. Further, the study also shows that genetic algorithm provides an accurate pattern of oil slick in SCNB data. This is shown by $90 \%$ for oil spill, $3 \%$ look-alike and $7 \%$ for sea roughness using the receiver-operational characteristics (ROC) curve.The GA also shows excellent performance of oil spill detection in SCNB data with smallest standard error of 0.11 and a $\rho$ value of 0.0000057 . In conclusion, the genetic algorithm can be used as an automatic detection tool for oil spill in RADARSAT-2 SAR satellite data such as SCNB.

\section{References}

Alpers W. (2002), Remote sensing of oil spills, Proceedings of the symposium "Maritime Disaster Management", King Fahd University of Petroleum and Minerals, Dhahran, Saudi Arabia,pp. 19-23.

Brekke C. and Solberg A. (2005), Oil Spill Detection by Satellite Remote Sensing, Remote Sensing of Environment, 95, 1-13.

Choudhury I. and Chakraborty M. (2006), SAR signature investigation of rice crop using RADARSAT data, International Journal of Remote Sensing, 27, 519-534.

Davis L. (1991), The Handbook of Genetic Algorithms. Van Nostran Reingold, New York.

Fiscella B., Giancaspro A., Nirchio, F., Pavese, P. and Trivero P. (2000), Oil Spill Detection Using Marine SAR Images, International Journal of Remote Sensing, 21, 3561-3566.

Frate F.D., Petrocchi A., Lichtenegger J. and Calabresi G. (2000), Neural Networks for Oil Spill Detection Using ERSSAR Data, IEEE Transactions on Geoscience and Remote Sensing, 38,2282 - 2287.

Garcia-Pineda O., MacDonald I.R., Li X., Jackson C.R. and Pichel W.G. (2013), Oil Spill Mapping and Measurement in the Gulf of Mexico With Textural Classifier Neural Network Algorithm (TCNNA), Selected Topics in Applied Earth Observations and Remote Sensing, 99,1-9.

Ivanov A., He, M. and Fang M.Q. (2002), Oil spill detection with the RADARSAT SAR in the waters of the Yellow and East Sea: A case study, CD of 23rd Asian Conferenceon Remote Sensing, 13-17 November 2002, Nepal, Asian Remote Sensing Society, Japan. 1, 1-8.

Kahlouche S., Achour K. and Benkhelif M. (2002), A new approach to image segmentation using genetic algorithm with mathematical morphology: Proceedings of the 2002 WSEAS International Conferences, Cadiz, Spain, June 12-16, 2002. www.wseas.us/e library/conferences/spain2002/papers/443-164.pdf,1-5.

Marghany M. (2013), Genetic Algorithm for Oil Spill Automatic Detection from Envisat Satellite Data. In: Computational Science and Its Applications-ICCSA 2013, Beniamino Murgante, Sanjay Misra, Maurizio Carlini, Carmelo M. Torre, Hong-Quang Nguyen, David Taniar, Bernady O. Apduhan and Osvaldo Gervas (Eds), Springer Berlin Heidelberg, New York.

Marghany M. and Hashim M. (2011), Comparative algorithms for oil spill detection from multi mode RADARSAT-1 SAR satellite data. In: Computational Science and Its Applications-ICCSA 2011, Springer Berlin Heidelberg, New York.

MDA (2009), RADARSAT-2 product description. [http://www. gs.mdacorporation.com]. [Accessed on March 7 2014].

Michalewicz Z. (1994), Genetic Algorithms+Data Structures, Evolution Programs, Springer-Verlang, New York.

RADARSAT-2(2014),Satellite Charcteristics,[http:||www.asc.csa.gc.ca/satellite/radarsat-tableau.asp],[Acessed on March 7 2014].

Shirvany R., Chabert M. and Tourneret J.Y. (2012), Ship and Oil-Spill Detection Using the Degree of Polarization in Linear and Hybrid/Compact Dual-Pol SAR, Selected Topics in Applied Earth Observations and Remote Sensing, 5, 885-892.

Sivanandam S.N. and Deepa S.N. (2008), Introduction to Genetic Algorithms. Springer Berlin Heidelberg, New York.

Skrunes S., Brekke C. and Eltoft T. (2012), An Experimental Study on Oil Spill Characterization by Multi-Polarization SAR, Proceedings of European Conference on Synthetic Aperture Radar, Nuremberg, Germany, 139-142.

Topouzelis K., Karathanassi V., Pavlakis P. and Rokos D. (2009), Potentiality of Feed Forward Neural Networks for Classifying Dark Formations to Oil Spills and Look-alikes, Geocarto International, 24, 179-19. 
Topouzelis K., Karathanassi, V., Pavlakis, P. and Rokos D. (2007), Detection and Discrimination between Oil Spills and Look-alike Phenomena through Neural Networks, ISPRS Journal Photogrametry Remote Sensing, 62, 264-270.

Velotto D., Migliaccio M., Nunziata F. and Lehner S. (2011), Dual-Polarized TerraSAR-X Data for Oil-Spill Observation, IEEE Transactions on Geoscience and Remote Sensing, 49, 4751-4762.

Zangari G., (2010), Risk of global climate change by BP oil spill. [www.associazionegeofisica.it/OilSpill.pdf], [Access on March 7 2014].

Zhang B., Perrie W., Li X. and Pichel W. (2011), Mapping sea surface oil slicks using RADARSAT-2 quad-polarization SAR image, Geophysical Research Letter, 38, L10602.

Zhang Y., Lin, H., Liu Q., Hu J., Li X. and Yeung K. (2012), Oil-spill monitoring in the coastal waters of Hong Kong and vicinity, Marine Geodesy, 35, 93-106. 